\title{
Aspectos Constitucionais das Emprêsas de Serviço Público
}

OCÉLIO DE MEDEIROS

\author{
I - EXPLICAÇÃO DO PROBLEMA - COMPLEXIDADE DE FORMAS \\ DE PRESTAÇÃO DE SERVIÇO PÚBLICO E SERVIÇO PRIVADO
}

$\mathrm{E}_{\mathrm{M}}$

M se tratando doz aspectos constitucionais dos Serviços de Utilidade Pública no Brasil deve-se ter em vista, precipuamente, o complexo problema da regulamentação dêsses serviços, além da natureza e classificação dos mesmos, em face da experiência brasileira.

Impõe-se, ainda, considerar a experiência nacional, em face dos diplomas anteriores, bem como dos dispositivos da Constituição de 18 de setembro de 1946, tanto os que especificamente se referem aos serviços públicos explorados mediante concessão como os que, mais direta ou indiretamente, interessam a êsses serviços e a outros tipos de utilidades públicas.

Necessário se torna, portanto, promover, inicialmente, a um levantamento na Ad̛ministração Brasileira, no tocante às formas objetivas de prestação de serviço público, e a uma análise do Texto Constitucional, com o objetivo de destacar aqueles dispositivos.

Diarite dessa explicação do problema, definem-se etapas de investigação e estudos, adiante seguides, para tratamento mais objetivo das disposições específicas sôbre o regime concessionário.

\section{II - FORMAS DE PRESTAÇÃO DO SERLITCO PÚBLICO}

Elementarmente se tem considerado que a administração, através da qual o serviço público é prestado pelo Estado, compreende entidades que se enquadram em duas grandes classes: Administração direta (unidades administrativas do Govêrno, diretamente subordinadas e enquadradas num sistema de hierarquia de órgãos de direção) e Administração indiretas (entes com características peculiares que as distinguem das unidades administrativas do govêrno, como autarquias e entidades para-estatais, que possuem personalidade jurídica de Direito Público, capacidade de auto-administração, suficiência financeira e mais liberdade de atribuições na esfera de seus interêsses e objetivos).

O Serviço Público, porém, não se exgota nessas formas elementares de administração direta e indireta. Nem tampouco se expande através das for- 
mas complementares de arrendamento (O Sierviço Público que envolve patrimônio do Estado e que é outorgado ao particular para que preste o serviço de modo lucrativo, pondo em funcionamento êsse patrimônio, mediante condições especiais de gerência e exploração) e concessão (o serviço público prestado por emprêsa privada, com patrimônio privado, reversível ou não, mas sujeito ao interêsse público sob condições de regulamentação e contrôle especial da parte do Estado, mediante cláusulas contratuais, obrigações e deveres de ambas as partes).

Os autores, em geral, admitem como formas clássicas de prestação de serviço público a administração direta, a administração indireta, a concessão e $\alpha$ arrendamento.

Após debates e informações doutrinárias em tôrno do Serviço Público, podemos estabelecer os seguintes enunciados, tendo particularmente em vista os princípios políticos da estruturação do Estado Brasileiro:

a) Há Serviço Públicơ e há Serviço Privado, da mesma maneira comu há pessoa de direito público e pessoa de direito privado. A natureza da pessoa, entretanto, não se caracteriza, concomitantemente, pela natureza do Serviço prestado.

b) Há características de distinção entre Serviço Público e Serviço Privado. Essas características, porém, não obedecem a padrões rígidos, pois há Serviço Público com características de Serviço Privado como Serviço Privado com características de Serviço Público.

c) Na conceituação do Serviço Público é preciso considerar nãơ só a natureza do Serviço como a doo órgão que presta êsse serviço. Há órgãos públicos que prestam tantos serviços públicos como os que podem ser considerados como tradicionalmente privados. Enfim, há órgãos privados que, além de prestarem serviços privados, prestam também serviços tradicionalmente considerados como públicos.

d) O conceito de Serviço Público não encontra limites exclusivos na doutrina jurídica e administrativa. Está em função do pensamento das épocas, das concepções do Estado e das ideologias políticas dos Govêrnos. Antes de qualquer conceituação de Serviço Público impõe-se a abstração das doutrinas, sendo necessário analizar, fundamentalmente, tanto a estrutura estatal, como o sistema administrativo do Govêrno ou o regime governamental da Administração, sob os princípios políticos que orientam a organização das nações em determinada época.

e) No decorrer dos últimos vinte e cinco anos, os conceitos clássicos de Serviço Público, no Brasil, não só têm sofrido evolução, como resultado do crescente grau de interferência estatal nos domínios tradicionais da economia privada, como até mesmo perversão.

f) Na prestação dos Serviços Públicos, é preciso ter em vista não só as formas como os próprioș regimes que se exprimem nas condições especiais em que o serviço é prestado por essas formas. Dentre êsses regimes, tem tomado impulso, nos últimos anos, o da cooperação internacional e o da assistência técnica mediante contratos ou acôrdos.

g) No setor da administração indireta do Estado, a proliferação das autarquias e das chamadas entidades para-estatais, institutos de personalidade 
jurídica de Direito Público mas de artificiosa distinção, criou um sistema administrativo cuja expansão, demonstrando o transbordo das funções estatais muito além dos limites clássicos da ação do Poder Público, se torna cada vez mais desenvolvida e complexa. A caracterização dêsses entes, que compreendem as mais diversas classes e os mais variados tipos conforme as suas finalidades existenciais, vai além de padrões jurídicos e administrativos consagrados pela doutrina, podendo-se admitir que os mesmos se revestem de inovações criadas pelo próprio Direito Positivo do Brasil.

h) No estudo do Serviço Público, existe uma terminologia complexa, ainda por sistematizar, e onde os têrmos requerem conceitos próprios, na conformidade do ramo da Ciência de que são objtos.

i) Através de tôdas as discussões, tanto em tôrno do conceito de Serviço Público como das formas de prestação, verificamos que o Serviço Público ultrapassa o enquadramento propriamente administrativo do Govêrno e dá lugar a diversas expressões de sentido controvertido e complexo no Direito Brasileiro. No estudo da prestação do Serviço Público no Brasil, enunciam-se vários itens que estão ainda por serem sistematizados em classes, como os seguintes:

I - No Estado Brasileiro, o Serviço Público, tanto resultante da pleto:a e da interferência do Govêrno, como da interferente cooperação competitiva da própria iniciativa privada, se manifesta através de um sistema crescente e complexo, cuja nomenclatura desafia ainda sérias pesquisas de sistematização.

II - No interêsse de servir a essas pesquizas, relacionamos a seguir diversas expressões, de conceito controvertido e sentido complexo, que exprimem formas de prestação de Serviço Público.

III - Nesse relacionamento, tivemos em vista uma simples enumeração de pessoas, quer de direito Público quer de Direito Privado, que se votam à prestação do Serviço Público, sem nenhuma preocupação de estabelecer grupos ou classes, bem como de eliminar sinonímias. São as seguintes:

a) Administração Direta - Órgãos de Administração e do Govêrno. Unidades Administrativas dơ Govêrno da União, dos Estados, dos Municípics. dos Territórios, dos Distritos, Ministérios, Departamentos, Serviços, Secooes, Comissões Especiais. Diretorias. Divisões. Secretarias.

b) Administração Indireta - Autarquias. Entidades Para-Estatais. Autarquias Territoriais econômicas, culturais, sociais, financeiras e de outros tipos. Entes antônomos. "Authorites". Institutos.

c) Administrações Diretas com funcionamento de Administração Indireta. Unidades de características Mixta: Administrações Territoriais.

d) Administrações Delegadas.

e) Sociedades de Economia Mista. Preponderância de Capitais Públicos. Preponderância de Capitais Privados.

f) Estatização. Monopólios Legais. "Regies". Serviços de Patrimônio Estatal. Emprêsas Incorporadas. prêras.

g) Nacionalização. Nacionalização de capitais. Nacionalização de Em- 
h) Municipalização. "Municipal Ownership". "Municipal operation". Socialização Municipal.

i) Serviços Públicos socializados. Mistas.

j) Fundações. Fundações Públicas. Fundações Privadas. Fundações

k) Ccoperativas. Cooperativas Públicas. Cooperativas Privadas. Cooperativas Mistas (Vêr Decreto-lei n. ${ }^{\circ}$ 5.893, de 19-10-943).

1) Arrendamentos. Arrandamentos de Emprêsa. Arrendamentos de Serviços.

m) Serviços Públicos resultantes de acôrdos e contratos de Locação. Serviços Inter-Estaduais. Serviços Internacionais. Contratos de Assistência Técnica.

n) Sociedades de Utilidade Pública. Associação de classe. Sindicatos.

o) Concessões. Serviçoz Públicos concedidos. Serviços Públicos de Exploração Lucrativa. Utilidades Públicas (Public Utilities). Serviços de Utilidade Pública.

p) "Franchises". Licenças. Autorizações de operação e funcionamentơ.

q) Bancos de Organização Especial. Bancos com participação de impostos e taxas. Bancos de crédito cooperativo. Bancos de Dezenvolvimento Econômico.

r) Entidades mantidas pelo comércio e pela Indústria para a prestação de Serviço Público.

s) Emprêsas privadas de comércio e indústria, não sob contrôle especial, mas sob regulamentação legal. Emprêsas públicas competitivas e concorrentes.

Esses itens se referem, em geral, a espécies que se classificam em gêneros. São individualizações que, em alguns casos, constituem simples fases mas formas de prestações. A caracterização de cada um dêsses itens, entretanto, oferece conceitos que constituem campos de tratamento específico e que ultrapassam à espera do próprio Direito.

Em qualquer emprêsa, há propósitos e processos que podem ser tanto de natureza pública como privada. Quanto mais existir predominância de propósitos e processos de natureza pública, mais de interêsse público são os :erviços prestados. Nos Serviços de Utilidade Pública, por isto mesmo, os propósitos e processos são predominantemente públicos, em comparação com os propósitos e processos de emprêsa privada que possuem.

\section{III - A POSIÇÃO DOS GOVERNOS FEDERAL, ESTADUAL, MUNICIPAL, TERRITORIAL E DISTRITAL EM FACE DOS SERVIÇOS PÚBLICOS CONCEDIDOS}

O que caracteriza, fundamentalmente, o Estado Federal, é a coexistência, que se expressa na União indissolúvel, de entidades político-administrativas, representadas por áreas geográficas que, apesar de serem partes do todo, possuem limitado poder de auto-organização, auto-govêrno e auto-adininistração, de direito ou de fato, com esferas próprias de competência, no seu ajustaniento à ordem constitucional. 
Não há, pròpriamente, Estado Federal, sob a concepção de um modêlo rígido, mas sim Estados Federais, isto é, situações de organização estatal que independem de formas governamentais e variam de país para país, de povo para povo, de época para época, conforme as condições existenciais de cada nação. Há tipos de Estado, evidentemente, e o Estado Federal é um dêšes tipos, mas sob diversas modalidades e características.

$\mathrm{Na}$ conformidade do art. $10^{\circ}$ da Constituição de 18 de Setembro de 1946, ao tratar da organização Federal, pode-se considerar que a Federação e a República foram interpretados como um efeito dos Estados Unidos do Brasil. Isto é, Estados pre-existentes à Constituição, Unidos, deliberaram manter, sob o regime representativo, a Federação (tipo estatal) e a República (forma governamental).

Aos mais autorizados comentadores da Constituição de 18 de Setembro de 1946 tem escapado uma análise mais objetiva dêsse dispositivo. Nessa análise, é preciso ter em vista não apenas a Ciência Política, com sua doutrina juríaica, suas classificações teóricas e seus modelos estatais consagrados. E' necessário, ainda, e sobretudo, objetivar a realidade brasileira, a base sociológica da formação nacional, experiências, reações e tendências dơ povo através da ação organizacional das fôrças que o representam.

"A União", conforme o $\S 10^{\circ}$ do art. $10^{\circ}$ da Constituição, "Compreende, além dos Estados" (isto é, entidades federativas, federais ou federadas básicas), "o Distrito Federal e os Territórios" (partes complementares e existenciais dessa União).

Desdobrando-se o mencionado parágrafo, verificaremos:

a) A União em si, como expressão do todo, integrando-se das partes ou membros que a compreendem, integrando-as (Estados, Distrito Federal, Territórios).

b) Os Estados. "Cada Estado", conforme estatui o art. 18, "Se regerá pela Constituição e pelas Leis que adotar, observadas os princípios estabelecidos" na Constituição. Na observância dêsses princípios, - Os Estados coexistem na estrutura federativa brasileira, constituindo-se; organizando-se, governando-se e administrando-se a si mesmo pelo exercício dos seus próprios poderes, nos quais se incluem os residuais que lhes são reservados: - "Todos os poderes que, implícita ou explicitamente, não lhes sejam vedados" pela Constituição.

c) O Distrito Federal, que é a Capital ou sede da União. Segundo o art 26, "O Distrito Federal será administrado por um Prefeito, de nomeação do Presidente da República, e terá Câmara, eleita ફ̦elo povo, com funções legislativas". Sua organização administrativa e judiciária, porém, será regulada por Lei Federal (art. 25).

d) Os Territórios, entidades constitutivas da União, e que, como o Distrito Federal, têm a sua organização administrativa e judiciária regulada por Lei Federal, na forma do que dispõe o artigo 25 da Constituição. Ao contrário, porénı, do que ocorre com o Distrito Federal, as nomeações dos Governadores dos Territórios Federais, feitos pelo Presidente da República, não dependem de aprovação do Senado. Por outro lado, também ao contrário do 
Distrito Federal, não possuem os Territórios, Câmaras eleitas pelo povo, com funções legislativas.

Como vemos, cada tipo de unidade político-administrativa, constitutiva da União, possui um sistema diferente de competência.

Além do mais, mesmo que, num plano de igualdade, as unidades do mesmo tipo, como os Estados por exemplo, possuam indistintamente a mesma soma de poderes, as competências são maiores ou menores conforme as próprias condições regionais de cada um. E' o caso, por exemplo, de Estados que possuem rios interiores, que não ultrapassam os limites das fronteiras estaduais, muito poucos aliás. Ocorrendo, nesses rios, possibilidades de potencial hidro-elétrico para aproveitamento em serviço público concedidos, a Lei $\mathrm{Fe}-$ deral deverá prever uma competência mais larga para essas entidades, no que diz respeito ao regime concessionário.

Há a considerar, ademais, o problema dos Municípios, que coexistem autônomamente nas áreas dos Estados e, com uma organização de fato diferente, na área dos Territórios.

A autonomia dos Municípios, segundo preceitua o artigo 28, será assegurada fundamentalmente pela eleição do Prefeito e dos vereadores (inciso I), pela administraçã̃o própria, no que concerne ao seu peculiar interêsse (inciso II); e, especialmente, (a) pela decretação e arrecadação dos tributos de sua competência e decretação de suas rendas, bem como (b) pela organização dos serviços públicos locais. Deixando de lado a situação anômala e contraditória, de fato, dos Municípios Territoriais, observamos que há Municípios Estaduais que não possuem os mesmos limites gerais de autonomia, o que vale dizer, de capacidade de auto-organização e auto-govêrno pelo exercício de uma esfera própria de competência, dependendo de condições geográficas (estâncias hidro-minerais, bases militares ou portos militares, sequrança nacional, defesa externa).

Se a Lei "Deverá dispor sôbre o regime das emprêsas concessionárias de serviços públicos federais, estaduais e municipais, certamente não poderá deixar de lado êsse complexo problema de competência exclusiva, supletiva ou concorrente, além da própria natureza das emprêsas, que podem ser federais, territoriais, distritais, estaduais ou municipais, tanto pela sua localização nas áreas dessas entidades como também pelo vínculo jurídico de competência do poder concedente.

O Estado Federal, conforme o tipo brasileiro, supõe a existência de direitos locais diversos, como expressão positiva do exercício de um limite de competência. Isto vale reconhecer que, além do Direito Federal ou Central, que decorre da União, existe o Direito Local, conforme o nível de govêrno de onde emanar e que possui características próprias de classe. Daí o Direito Distrital, o Direito Territorial, e Direito Estadual e o Direito Municipal como tipos de Direito Local, resultantes da manifestação jurídica de competências exclusivas, supletivas e concorrentes, exprimindo uma órbita de poder.

A maioria dos Municípios Brasileiros, é bem verdade, pouco terá a ver com regimes concessionários de serviços públicos, em virtude de condições incapazes de atrair os investimentos das emprêsas privadas. São municípios precários, de pouca densidade, inexpressiva concentração de populações ur- 
banas, capacidade tributária restrita e nível de consumo reduzido. São municípios que, sob o impacto de fatores sócio-econômicos, são fatalmente levados a municipalizar os seus serviços públicos, financiando-os e administrando-os nos limites de suas escassas possiibilidades técnicas e financeiras.

Mas além dêsses municípios, em sua maioria rurais, há os grandes Municípios, como os de São Paulo, Santos, Salvador, Pôrto Alegre, Recife e outras capitais, onde emprêsas privadas encontram condições favoráveis a concorrer para a obtenção de concessõez de serviço público de várias espécies.

Acresce, ainda, que geogràficamente circunvizinhos dêsses grandes conglomerados urbanos, pode ocorrer a existência de municípios ou distritos rurais aos quais possam ser extendidos os serviços públicos da concessão, sem nenhum conflito de competência. Além da hipótese do agrupamento de municípios para resolver problemas ccncessionários de serviços públicos de interêsse comum, há outros que precisam ser considerados, como os de sobras de energia, criação de subestações, extensão de linhas e custos marginais.

A posição dos Governos Federal, Territorial, Distrital, Estadual e Municipal consiste, portanto numa obra de coordenação de competências, na Lei Federal que disporá sôbre o regime das emprêsas concessionárias de serviços públicos.

\section{IV - AS FONTES JURÍdiCAS DA REGULAMENTAÇÃO DOS SERVIÇOS} DE UTILIDADE PÚBLICA

A expressão "Regulamentação dos Serviços de Utilidade Pública" possui um sentido amplo e envolvente.

A própria palavra "regulamentzção", no "Direito Brasileiro", ainda não possui um conceito definido. E' até mesmo tida, por alguns, como imprópria. Dada a imprecisão linguística, há quem prefira o têrmo "regulação", de vclho emiprêgo nas referências jurídico-administrativas.

$\mathrm{Na}$ verdade, "regulamentação" não significa, apenas, "regimentação". Não exprime também a idéia de uma simples interferência do Estado no domínio privado da Economia. Vai muito além, por traduzir, acima de tucio, a existência de um contrôle todo especial sôbre as emprêsas de utilidade pública. Seu sentido supera a própria regulamentação que o Estado exerce de diferentes maneiras, como indiscutível manifestação de seu poder de Polícia, nos diversos setores da economia privada, prevendo abusos; dispondo sôbre sistemas de abastecimento em épocas de escassês de produção e consumo; estabelecendo atividades públicas comerciais e industriais de caráter competitivo ou concorrente; tentando o nivelamento dos preços; fixando preços mínimos ou de teto; ou ainda influindo, quer indireta quer diretamente, na Lei da oferta $e$ da procura.

Regulamentação é todo um sistema, legal e administrativo, consubstanciando-se de processos e propósitos, e que, por visar a objetivos definidos, expressa um contrôle especial que o Estado exerce até mesmo na vida íntinıa das utilidades públicas, tendo particularmente em vista suas próprias funções e finalidades. 
Nos Estados Unidos da América, em cuja Constituição se inscrevem apenas as linhas mestras da estrutura e do funcioamento do Estado, visando mais os princípios fundamentais da organização federalista do que as minucias jurídicas dos direitos individuais e coletivos, o problema da regulamentação das utilidades públicas encontrou suas fontes históricas nas decisões da Côrte Suprema. A simples legislação não bastava, por ter sido arguida, de início, como atentatória à livre emprêsa, afetando assim os direitos privados. sobretudo no tocante à propriedade. Teve a Côrte Suprema, em diversas oportunidades, de estabelecer limites a êsses direitos, principalmente em se tratando de propriedade de "interêsse público" como os das utilidades públicas. Realmente das decisões da Côrte Suprema é que o problema da regulamentação foi ganhando etapas históricas e decisivas.

No Brasil, o caso tem tido diferente, destacadamente a partir de 1930 . As próprias Constituições, a partir dessa época passaram a inscrever em seu texto dispositivos expressos, de modo que as fontes da regulamentação dos Serviços de Utilidade Pública passaram a ser constitucionais, não judiciais, a despeito da existência de substanciosas decisões judiciárias e pareceres sôbre - problema, no regime da primeira Constituição Republicana, que se caracterizava por omissões e silêncios segundơ as concepções ideológicas da implantação da República.

Não sendo nosso objetivo promover a investigações de História Constitucional, consideramos apenas, nesse particular, o diploma de 1946.

Antes, porém, de tratarmos dơ assunto, julgamos da máxima importância recapitular o trabalho da Assembléia Constituinte, quando debateu a parte do Ante-Projeto da Constituição referente aos serviços públicos concedidos e os princípios fundamentais da elaboração tarifária.

\section{$\mathrm{V}$ - ALGUNS A'SPECTOS DOS DEBATES DA ASSEMBLÉIA NACIONAL CONSTITUINTE SÔBRE OS SERVIÇOS PÚBLICOS EXPLORADOS MEDIANTE CONCESSÃO}

O Desembargador José Duarte, (1) na sua obra de exegese dos Textos constitucionais à luz dos trabalhos da Assembléia Constituinte, reuniu importantíssimo material sôbre o art. 151, facilitando a sua interpretação em virtude de expor, de maneira concreta, todos os principais elementos que influíram na redação definitiva do dispositivo. Seu estudo parte do ante-projeto, constante do art. $80^{\circ}$ e seu parágrafo único, așsim originàriamente redigido:

"Art. 8. ${ }^{\circ}$ As emprêsas concessionárias de serviço público federais, estaduais ou municipais deverão constituir com maioria de brasileiros a sua administração ou delegar a brasileiros todos os poderes de gerência.

Parágrafo único. A Lei Federal regulará a fiscalização e revisão das tarifas dos serviços públicos explorados por concessão para que, no interêsse coletivo, a retribuição do capital não impeça a expansão e melhoramentos dos serviços. A lei se aplicará às concessões feitas no regime anterior de tarifas estipuladas para todo o tempo de duração do contrato". 
O objetivo primordial da regulamentação tinha em vista, originàriamente, a nacionalização das emprêsas concessionárias. Muitas das emendas apresentadas tinham também êsse objetivo.

0 eminente jurisconsulto citado elaborou um sério trabalho de análise das emendas, conforme as discussões que o projeto sofreu na Comissão Constitucional.

Essas emendas foram da autoria de Ataliba Nogueira e Costa Neto (modificativa) e Caires de Brito (substitutiva).

As discussões se processaram por partes: em primeiro lugar, o texto do âtigo e, por último, do parágrafo.

Defendendo a emenda substitutiva - "A Lei regulará a nacionalização das emprêsas concessionárias de serviçoz públicos federais, estaduais ou municipais" - Caires de Brito, demonstrou a conveniência da nacionalização das emprêsas cujos serviços foram reputados essenciais à segurança do país.

Na discussão do parágrafo único, com as emendas Costa Neto e Ataliba Nogueira, ressaltou Aliomar Baleeiro a influência da Constituição de 1934 na redação do dispositivo, tratando mais objetivamente da parte referente a tarifas, as quais, segundo o representante baiano, deveriam ser calculádas "à base do custo histórico".

Com respeito a êsse problema, o Desembargador José Duarte resumiu, do modo a seguir, a exposição de Aliomar Baleeiro:

"A finalidade dêsse dispositivo, tanto na Constituição de 1934, quanto na de 1937, onde o preceito é análogo, e, ainda, no anteprojeto, é, estabelecer a regulamentação efetiva dos serviços públicos, isto é, que essas tarifas sejam, realmente, o justo preço de um serviço e não fonte de locupletamento para as emprêsas, garantida, sempre, a eficiência dos serviços. Isto, porém, com o desenvolvimentơ moderno, dos serviços de utilidade pública, traz problemas de tal complexidade, tão sérios, que nos obrigam a criar os órgãos técnicos adequados a êsże fim. Hoje, as emprêsas de serviços públicos tem tal desenvolvimento, abrangem interêsses tamanhos, compreendem circunscrições geográficas tão diversas, abraçam tal número de pessoas e jogam com tais capitais, que se diz, com muita razão, que são, hoje, o problema mais sério das demucracias. Isto porque essas emprêsas, nas grandes potências, tendem a formar os chamados holdings ou seja a concentração piramiral das emprêsas. Este fato, observado há cêrca de quarenta anos, vem empolgando os estudos de direito administrativo e representando um dos problemas mais importantes do nosso tempo. Mesmo para nós, brasileiros, diz êle, existe já o problema, porque as emprêsas de eletricidade, sabemos estarem tôdas sob o guante de um holging nacional, que as superintende ou controla, por sua vez ligado a um grupo norte-americano ou canadense, que, também, a seu turno, se filia ao sistema de "United Bonds \& Shares Co."

Um dos maiores problemas no trato das emprêsas de serviços públiccs é o do cálculo das tarifas. As emprêsas, tendem, sempre, a sustentar o critério do custo de reposição atual, isto é, as tarifas devem permitir, como base para o cálculo da remuneração ao seu capital, o que teriam de dispender se tivessem de adquirir, no momento, todo o seu maquinário, tôdas as suas instalações, todos os seus bens e serviços. 
A isto se opõe a doutrina mais abalizada de que a tarifa deve ser calculada pelo custo histórico. A emprêsa declara quanto inverteu nas instalações dessas máquinas, e como deve ter uma conta de amortização, o valor de seus bens, tanto para efeito do cálculo de remuneração do capital, quanto para a reversão e encampação, há de basear-se no que inverteu, efetivamente, meṇos a desvalorização.

Êste o conceito do custo histórico, que se opõe ao de reposição atual. Nos Estados Unidos, depois de Roosevelt, o assunto vem sendo resolvido da maneira que explicou". (2)

As discussões, em tôrno do parágrafơ único, regrediram por diversas vêzes às maneiras como o problema foi tratado nas Constituições anteriores (1934 e 1937). Por fim, foi votada a emenda Costa Neto ("A Lei regulará a fiscalização e a revisão das tarifas dos serviços explorados por concessão, a fim de que os lucros dos concessionários, não excedendo à justa remuneração do capital, lhes permita atender as necessidades do melhoramento e expansão daqueles serviços").

Nos debates em tôrno dêsse assunto, confrontaram-se os argumentos favoráveis, de um lado, ao custo histórico, e, outro, ao custo de reprodução, em face da exp̉ressão "jưsta remuneração do capital", constante do texto aprovado. Diversas emendas surgiram, valendo ressaltar as de Negreiros Falcão e Carlos Prestes.

Vieira de Melo, ao pedir destaque para a emenda Carlos Prestes, suscitou o problema da "justa remuneração de capital", frase arguida de imprecisão.

Resumindo a opinião do legislador constituinte, o Desembargador José Duarte, relatou o seguinte:

"Agora a "justa remuneração do capital". Que Capital? E' uma interpretação. Que é justo valor atual das instalações de uma companhia concessicnária de serviços públicos? E' outra interpretação. Precisamente, aqui está o segredo da questão. Não adianta o legislador constituinte estabelecer que as tarifas sejam fixadas, tendo em vista a justa remuneração do capital, se não determinar qual o critério para a avaliação desse Capital".

As discussões que se processaram, em destaque de certas emendas, que por fim foram regeitadas, submeteram os serviços públicos concedidos ao debate mais amplo possível, não só quanto ao custo histórico e o de reprodução, cumo ainda quanto à nacionalização, à estatização e ao monopólio.

\section{VI - O ARTIGO 151 DA CONSTITUIÇÃO DE 18 DE SETEMBRO DE 1946}

A Constituição, no seu artigo 151, do título V, Da Ordem econômica e social, estatui que "a Lei disporá sôbre o regime das emprêsas concessionárias de serviços públicos federais, estaduais e municipais".

Evidentemente, a Lei prevista, no caso, terá de ser federal. Deverá ser uma Lei orgânica, ou mesmo um código, de sentido amplo, com definição de princípiós e amoldada à interpretação e à aplicação dos diversos preceitos inscritos no texto constitucional, aplicáveis aos serviços públicos concedidos. 
O dispositivo citado, entretanto, possui um sentido restrito. Refere-se apenas ao regime das emprêsas concessionárias, excluindơ portanto utilidades publicas que prestam serviços sob outras formas, além da concessão e da administração indireta. Isto é, excluiu emprêsas de serviço público de administração indireta, sociedades de economia mista, companhias estatizadas e municipalizadas que prestam ou podem prestar os mesmos serviços que são objeto de concessão e que representam ou podem representar empreendimentos ou utilidades públicas diversas como energia e luz, transportes coletivos, gás, água, comunicações e outros. Embora excluídas dos objetivos expressos do artigo essas formas de serviço público, desde que devidamente caracterizadas e definidas, podem ser objeto de um capítulo ou título especial na referida Lei ou Código, em virtude de sua natureza, relações jurídico-administrativas e funções no domínio social e econômico, além dos problemas competitivos.

A expressão "regime das emprêsas" possui uma significação bastante ampla. "Regime" se refere tanto a "status" como a normas diversas em variađos setores da vida das emprêsas: sua origem, suas finalidades ou objetivos; sua organização e localização; sua estrutura e funcionamento; suas funções e contrôle de execução; enfim, a tôdas as condições contratuais, desde a definiçãc de sua natureza às formas de adequado contrôle da justa retribuição dos investimentos, pelo pagamento de tarifas razoáveis, tanto a fim de que o lucro não seja tão alto como também não seja tão baixo de modo a não permitir a justa retribuição ou implicar na deficiência dos serviços em prejuízo do público e do Estado. Nesse regime, há uma série de responsabilidades e obrigações tanto da parte das emprêsas como do público e do Estado representado pelos diversos níveis de govêrno, e que precisam ser definidas.

O dispositivo também se refere expressamente a emprêsas "federais", "estaduais" e "municipais". Não quer isto dizer que as emprêsas sejam dêsses governos, porque são concessionárias e constituem a pessoas jurídicas de Direito Privado. O artigo, com essas referências expressas, teve com vista o problema do direito de contrôle da parte dos níveis de govêrno e, sobretudo, das áreas, ou melhor, das circunscrições ou esferas de competência, em que as emprêsas se situam ou operam. Nessas áreas, há ainda os Territórios, nos quais se integram municípios e distrito, e o Distrito Federal, que sendo diferente do Estado e do Município e sem ser o Govêrno Federal, representa, como os Territórios, uma área especial, uma esfera "sui-generis" de competência na estrutura federal.

A Lei preconizada, que poderá ser um código, não deverá deixar de atender, portanto, ao problema da separação e da redistribuição de competências, respeitando prerrogativas jurídicas e conveniências de descentralização administrativa. Por isto mesmo, não poderá excluir a legislação supletiva ou complementar, tanto em face das disposições expressas nesse sentido como ainda das de competências implícita e explícita, incursionando na zona dos chamados poderes residuais. Problemas dessa natureza e magnitude interessam à própria estruturação legal do sistema federativo, estabelecida na Constituição através de normas gerais, cuja suplementação tanto pode depender de legislação complementar como de decisões judiciárias em casos de conflito. 
Aspecto fundamental da elaboração dessa Lei ou Código se consubstancia na necessidade do estabelecimento administrativo do órgão da natureza mais aconselhável (Departamento, Superintendência, Serviço Auxiliar, Conissão, Conselho) ou sistema de órgãos - para executar as disposições regulamentadoras das emprêsas, aplicando-as efetivamente. A simples existência ḋe dispositivos orgânicos ou a mera sistematização de artigos com objetivos especiais a que ficariam sujeitas as emprêsas, não bastariam para a melhor eficácia do recomendável contrôle do Estado. Uma simples Lei, sem a existência dos instrumentos administrativos destinados a aplicá-la, terá quase que os mesmos efeitos dos contratos de concessão, nos quais também se consubstanciam deveres e obrigações, quer da parte do Estado quer da parte das emprésas. Sôbre êsses aspectos administrativos trataremos em outra oportunidade. Apenas enunciamos aqui o problema da imperiosidade da existência de instrumentos administrativos, sem opinar pela sua natureza, destinados a aplicar, fiscalizar e controlar a Lei ou Código que "disporá sôbre o regime das emprêsas concessionárias", surpevionando-as, coordenando-as horizontalmente ou superintendendo-as, conforme é nosso ponto de vista a respeito.

O problema da regulamentação dos Serviços de Utilidade Pública, no Brasil, já não consiste no simples reconhecimento de sua necessidade. Já é objeto de disposições estatuídas. Depende apenas de melhor sistematização das Leis esparsas existentes e promover a uma revisão, que poderá implicar ern reestruturação, readaptação ou mesmo extinção de órgãos administrativos que, em diferentes níveis de govêrno, tratam especificamente do assunto. E', finalmente, problema de melhor efetivação dos dispositivos constitucionais .

Com efeito, a situação presente é a seguinte:

a) existem, no Brasil, várias emprêsas ou poderosos grupos de emprêsas que prestam serviço público, sob as mais variadas formas;

b) além dessas emprêsas ou grupos existentes, comprova-se a possibilidade de surgirem novos empreendimentos, sob o impacto de fatores como o desenvolvimento econômico nacional, o crescimento da população, a expansãu industrial, o progresso tecnologico, o aumento crescente das aglomerações urbanas em comparação com os índices das populações rurais, a elevação da rerda nacional e a necessidade de mais serviços e mais produtos pelas exigências de progresso das coletividades brasileiras;

c) sôbre os serviços de utilidade pública, principalmente os que operam em regime de concessão, já existem normas contratuais e legais consagradas, bem como uma legislação esparsa e destinada a certos setores especî́icos:

d) paralelamente a essa legislação, existem ainda diversos orgãos administrativos nos diferentes níveis de govêrno que direta ou indiretamente se manifestam em setores específicos dos serviços de utilidade Pública;

e) Além dessas Leis, normas, e órgãos, há disposit:'os constitucionais posteriores à sua existência e que carecem de interpretação e crmplementação legislativa, dispositivos êsses que tanto visam diretamente os Serviços de Utilidade Pública como aos mesmos interessam mais particularmente, $y \rightarrow r$ thes serem implìcitamente aplicáveis. 
Diante dêsse quadro de realidades que caracterizam a existência de riıt dos maiores problemas brasileiros, tem havido tentativas pioneiras de soluçäo parcial que implicam, em última análise, na regulamentação dos serviços de utilidade pública, ao influxo sobretudo da necessidade de dar eficácia a preceitos consagrados na Constituição de 18 de setembro de 1946.

Já existe, no Congresso Nacional, um projeto de regulamentação parcial, abrangendo exclusivamente as emprêsas concessionárias de energia elétrica.

Por outro lado, o Conselho Nacional de Economia, a quem incumbe, na forma da Constituição, "estudar a vida econômica do país e sugerir ao Poder competente as medidas que considerar necessárias" ( $§ 2 .^{\circ}$ do artigo 205), tratou também do assunto, elaborando um projeto sôbre energia elétrica.

A par dêsse projeto do Conselho Nacional de Economia, existem ainda sugestões e estudos, tanto da parte de órgãos especializados como de técnicos interessados no problema.

Dêsse modo, a realidade tem sido esta: a regulamentação dos serviços públicos, isto é, dos serviços de utilidade pública, tem sido encarada apenas paicialmente, através de estudos e projetos que visam sòmente as emprêsas de maior importância e que se votam a determinado ramo. Ainda não se teve em vista uma solução total e definitiva, capaz de dar mais efetividade aos dispositivos constitucionais. Não se cogitou, ainda, mais efetivamente, de um reestruturação dos órgãos especializados, de modo a encontrar uma solução administrativa mais consentânea com a realidade brasileira e com as necessidades de desenvolvimento dos serviços de utilidade pública, em face das exigências nacionais de progresso. Caberia ao Poder Público tomar a iniciativa das providências nesse sentido, através da instituição, tanto da esfera do Poder Executivo quanto na do Legislativo, de comissões especiais de estudos. inquéritos, levantamentos e pesquisas e que apresentassem, como resultados: dêsses trabalhos iniciais, as formulações legais e administrativas recomendáveis para o caso brasileiro.

\section{VII - LEVANTAMENTO DOS DISPOSITIVOS CONSTITUCIONAIS, DE INTERÊSSE DIRETO OU INDIRETO DAS EMPRÊSAS DE SERVIÇO PÚBLICO}

No estudo dos Serviços Públicos, principalmente dos prestados em regime de concessão, imperioso se torna investigar os diversos aspectos constitucionais, em face dos variados dispositivos do texto da Lei Maior e que se relacionam a diferentes ramos do Direito Positivo Brasileiro. Nessa investigação, abstraímos os serviços públicos de administração direta, que se ligam. aos fins clássicos do Estado e às funções tradicionais do Govêrno.

$\mathrm{Da}$ análise a que procedemos, à luz dos dispositivos, verificamos que os aspectos constitucionais do problema, pela sua natureza e amplitude, favorecem a existência de uma regulamentação geral, ainda por fazer, e que depende de Leis orgânicas complementares, a serem atualizadas e mesmo codificadas. Essa regulamentação, cedo ou tarde, terá de ser feita, apesar de envolverem problemas que, embora senda objeto de princípios constitucionais, 
ainda dependem da definição da atitude política do govêrno e da orientação legal da Administração.

Com efeito, há na Constituição artigos que objetivam específica e expressamente os serviços públicos prestados mediante regime de concessão. Mas, além dêsses dispositivos, há ainda outro que implícita ou explìcitamente afetam êsses serviços. Por outro lado, observa-se a existência de preceitos que se referem expressa, implícita ou explìcitamente a serviços públicos prestados por outras formas, como a indireta, a por delegação, por arrendamento, por atos administrativos, de onde resultam emprêsas, com personalidade jurídica de Direito Privado, sujeitas as mais diversas e contraditórias conceituações.

Qualquer obra de regulamentação ou mesmo de codificação dos dispositivos de regulamentação e contrôle especial de emprêsas que prestam serviços públicos, além dos órgãos da administração direta do Estado, encontrará na Constituição minúcias já consagradas, em dispositivos especiais.

Evidentemente, dada a diversidade dos preceitos estatuídos, as iniciativas pioneiras de legislação cơmplementar serão inicialmente esparsas e se condicionarão a atitudes que o Estado venha a tomar, em cada caso específico. São problemas variados, complexos e ingentes, que requerem tratamento específico, em cada situação definida capaz de provocar a reação construtiva do Poder Público.

Não é nosso objetivo apontar soluções e rumos, mas tão sòmente promover a um levantamento dos dispositivos que mais de perto interessam ao problema da regulamentação, ainda sujeita a debates e interpretações.

Nossa Constituição, evidentemente, pecou por excesso de discriminação. Parece que teve o legislador constituinte a preocupação de prolongar-lhe a vida, em face dos exemplos que implicaram, no decurso da face republicana, em movimentos de subversão que culminaram em derrogação de Constituições anacrônicas ou que apenas satisfizeram a necessidades momentâneas da vidn nacional. Mas antecipou-se demais, principalmente no domínio da ordem social e econômica pela adoção de medidas que, por um lado, de natureza capitalista são contraditórias no regime socialista ou, por outro lado, de natureza socialista são contraditórias ao regime capitalista. Sob êsse aspecto, quis evidentemente o legislador constituinte tentar conciliar, na Lei Maior, velho conflito entre os Direitos do Indivíduo e os direitos do Estado.

Dêsse modo, um govêrno que se implante com objetivos capitalistas ou outro que se instaure com nropósitos socialistas, conforme o momento eleitoral da vida brasileira, poderá manipular a Constituição e adaptações de princípios políticos e econômico-sociais estacionários ou avançados.

Não pôde o Estado deter o surto intervencionista que se vem processando a partir de 1930 e, por isto mesmo, não poderá regredir às formas do liberalismo em que a iniciativa individual possuia maior campo de expansão. Os problemas constitucionais brasileiros, por isto mesmo, em face da realidade sociológica e política, constituem eminentemente problemas de necessidade de conciliação jurídica de direitos individuais e sociais. Diante dessa necessidade de conciliação, teve o govêrno de limitar, recentemente, órbitas de :niciativa. fixando as próprias coordenadas do poder de intervenção no domínio econômico (Lei n. ${ }^{\circ} 1.522$, de 26 de dezembro de 1951). 
Após essas considerações de cunho interpretativo das conveniências objetivada pela Constituição na ordem social e econômica, passemos a investigar o texto, tendo em vista isolar, por um trabalho de levantamento, aqueles dispositivos que mais interessam, expressa, implícita ou explìcitamente, as emprêsas públicas e privadas que prestam serviço público, além das unidados de administração direta e indireta.

Já tivemos oportunidade de tratar, exaustivamente, em outras páginas, sôbre o serviço Público no campo doutrinário, tanto realizando investigações em tôrno de conceitos como promovendo análises sôbre as principais formas clássicas de prestação.

O problema da caracterização do Serviço Público, em nosso país, não pode ser considerado apenas sob o ângulo da filosofia jurídica, através das doutrinas. Tem de ser precipiamente examinado à luz das condições e conveniências nacionais, em face da interpretação de dispositivos expressos da Lei Maior.

Minuciosa análise deve ser inicialmente feita no tocante à competência da União, definida pelo art. $5 .^{\circ}$ e seus incisos e alíneas, do Título I, da Organização Federal, e Capítulo I, Disposições preliminares. Na delimitação dessa competência, há dispositivos que interessam particularmente às emprêsas de serviço público.

$\mathrm{Na}$ conformiidade dêsse artigo, o poder regulamentador da União sôbre certas atividades indiscutivelmente privadas é taxativo, em casos especificamente determinados. A produção de material bélico, por exemplo, depende de autorização especial e o seu comércio é objeto de fiscalização (inciso VI). Evidentemente, não se trata de serviço público, mas de produção e comércio nos quais a União possui um interêsse direto, por motivos substanciais de segurança.

No inciso VIII, há a consubstanciação de um monopólio estatal que se refere a cunhar e emitir moeda. Antigamente, sobretudo no tempo colonial, essa atividade também pertencia a emprêsa privada. Qualquer ourives pơdia cunhar moedas de ouro e prata, que entravam em circulação, desđe que possuissem as características de pêso e forma adotada pelo Govêrno. $O$ monopólio da cuhagem de moeda ainda não é total. Se considerarmos a moeda não apenas como metálica mas também como moeda papel verificaremos que a sua produção é também feita mediante contrato com emprêsas estrangeiras.

A instituição de Bancos de Emissão (inciso VIII) é também da competência da União, a quem incumbe fiscalizar as operações de crédito, de capitalizaçăo e seguro (inciso IX). No que diz respeito a Bancos de emissäo, a instituição pode ser feita mediante simples autorização, como realmente ccontece, pois ainda não possuímos uma Lei de Organização bancária capaz de estabelecer melhor sistema, constituído de um Banco Central do Govèrno Federal e seus ramos. O Banco do Brasil S. A., que é uma sociedade de econcmia mista, apenas exerce funções de fato de Banco Central.

Quanto ao plano nacional de viação, nos seus diversos setores, comrete à União apenas estabelecê-lo (inciso $\mathrm{X}$ ). Isso significa que serviços públicos de viação tanto prestados pelo Estado como por emprêsas privađas, devem sujeitar-se a êsse plano, submetendo as operações e o funcionamento ìs nor- 
mas e projetos adotados. A emprêsa privada pode se interessar não apenas na construção mediante contrato, mas ainda exploração lucrativa, inediante concessão de serviços públicos de viação, des que se enquadrem no plano nacional: Turnpikes, Park-ways, Freeways, auto-estradas, ferrovias, rodovias, pontes etc.

Monopólio característicamente estatal do serviço público observa-se com a manutenção, de competência da União, do serviço postal e do correio aéreo nacional (inciso $\mathrm{XI}$ ).

Pode a União, ainda, monopolizar outros serviços públicos, que the compete explorar diretamente. Não sendo de sua vantagem e conveniência explorar dêsse modo êsses serviços, pode fazê-lo mediante autorização ou concessăo. São os serviços, geralmente concorrentes e competitivos, de telégrafos, rád:o-comunicações, rádio-difusão, telefones inter-estaduais e internacionais, navegação aérea, vias-férreas que liguem portos marítimos a fronteiras nacionais o!1 transponham os limites de um Estado (inciso XII).

$\mathrm{Na}$ interpretação dêsse dispositivo, a exploração direta, por parte da União, nem sempre poderá implicar em monopólio público, pela natureza concorrente e competitiva de muitos dos Serviços de Utilidade Pública acima mencionados.

O Legislador Constituinte não se ateve, ao elaborar a inciso, a questões de terminologia, essencial aos fundamentos jurídicos dos serviços de utilidade pública.

Com efeito, o estudo do inciso revela formas incompletas e imprecisas de prestação de serviço, pois a exploração dos mesmos pode-se fazer da seguinte maneira:

a) diretamente ou

b) mediante autorizaçäo

c) ou concessão.

Exploração direta, exploração mediante autorização e exploração mediante concessão são figuras distintas, porém incompletas.

Além da exploração direta, que se fará pela administração como qualquer órgão, há ainda a administração indireta (autarquias, entidades para-estatais), e que não é a mesma coisa que mediante autorização ou concessão.

Administração indireta supõe a existência de entidades com personalidade jurídica de Direito Público, resultantes da surmenage administrativa do Estado.

Autorização é um simples ato, como o é também a licença, omitida no dispositivo.

Concessão é figura mais importante, implicando em contrato, conforme anteriormente expomos.

Outra parte de Serviços Públicos, que é da competência da União organizai, refcre-se à "defesa permanente contra os efeitos da sêca, das endemias rurais e das inundações" (inciso XIII). Essa organização envolve áreas, níveis de govêrno e problemas de prestação de serviços públicos sob as mais variadas formas: por administração direta, por administração indireta, por 
delegação, mediante concessão, licença, autorização etc. A competência de urganizar não implica necessàriamente na obrigação da prestação direta dos serviços.

Ainda no artigo $5 .^{\circ}$ configura-se a definição de uma área legislativa da competência federal, na qual, em alguns casos, não se exclui a legislação estadual supletiva ou complementar (inciso $\mathrm{XV}$ e suas alíneas, em inteligência coin o art. $6^{\circ}$ ). Essa área legislativa, de competência privada da União ou com a legislação local suplementar, interessa, em alguns casos, de modo particular, à prestação, sob diversas formas, do serviço público, como sejam:

I - Produção e consumo (sem excluir a legislação local supletiva). Serviços de Utilidade Pública são emprêsas que fornecem produtos-serviços destinados ao consuma público.

II - Desapropriação (competência do Govêrno Federal). Além do "eminent dominio", a desapropriação, nos serviços de utilidade pública, tem oferecido problemas da mais alta significação, relativos tanto às necessidades da emprêsa como às do próprio Estado.

III - Regime de portos e navegação de cabotagem. Há serviços de utilidade pública específicamente interessados nesse regime. Há ainda problemas de monapólio (estatal, público, legal etc.) ligados à navegaçãơ de cabotagem.

IV — Tráfego interestadual (sem excluir a legislação local supletiva).

V - Riqueza do sub-solo, mineração, metalúrgica, águas, energia elétrica, (sem excluir a legislação local supletiva). Sôbre êsses assuntos, de especial interêsse para determinados serviços de utilidade pública, a legislação brasileira está se desenvolvendo cada vez mais, dando lugar a formação de ramos especializados de Direito. Um centro de interêsse ainda novo, dependente de maiores investigações, liga-se aos minerais atômicos, sua exploração e utilização, nos serviços de utilidade pública, principalmente aos que produzem energia para diversos fins.

VI - Imigração e colonização. Êsses problemas, em si mesmos, são de tratamento específico. Mas há emprêsas de imigração e colonização, nacionais e estrangeiras, que se interessam por determinadas áreas e em privilégios de serviços públicos, que podem constituir a base econômica dos empreendimentos coloniais. Colônias Nacionais, Colồnias Agrícolas, Colônias de Fronteiras, Fundações como a Brasil Central e outras modalidades de empreendimentos associados aos problemas de imigração e colonização, quase sempre ampliam as suas finalidades básicas em operações que envolvem as mais variadas formas de prestação de serviços públicos.

Através da análise da Constituição, verificamos que ainda os seguintes dispositivos interessam, direta ou indiretamente, os serviços de utilidade pública:

I - Inciso III do art. $15^{\circ}$ (impostos da competência da União sôbre lubrificantes e combustíveis, minerais e energia elétrica (impôsto único);

II - Inciso IV do art. 15 (rendas e proventos de qualquer natureza). Em serviços de utilidade pública organizados com capital estrangeiro, há, ge- 
ralmer te, uma dupla tributação da renda: No país de origem dos capitais e no país em que êsses capitais operam, afetando assim as tarifas e a justa retrihuição dos capitais investidos.

III - Inciso V do art. 15 (transferência de fundos para o Exterior). Definem-se aí problemas especiais ligados a investimentos, retôrno de capital, remessa de dividendos, divisas, etc.

IV - Alínea $b$ do art. 28 (organização dos serviços públicos locais como elemento assecuratório da autonomia municipal). Problemas de muniripalização dos serviços.

V - Art. 31, vedando à União, aos Estados, ao Distrito Federal e aos Municípios lançar impostos sôbre bens, rendas e serviços uns dos outros, sem prejuízo da tributação dos serviços públicos concedidos;

VI - Parágrafo único do art. 31, pelo qual "os serviços públicos concediảos não gozam de isenção tributária, salvo quando competente ou quando a União a instituir em Lei especial, relativamente aos próprios serviços, tendo em vista o interêsse comum";

VII - Artigo 34 (bens da União: lagos e quaisquer correntes de água em terrenos do seu domínio ou que banhem mais de um Estado, sirvam de limites com outros páíses, ou se estendam a território estrangeiro etc.);

VIII - Artigo 35 (bens dos Estados: lagos e rios em terrenos do seu domínio e os que têm nascente e foz no território estadual);

IX .- Alínea $b$, do inciso I, do art. 48 (proibição de Deputados e Senadores, desde a expedição dos diplomas, de aceitar nem exercer comissão ou emprêgo remunerado "em emprêsa concessionária de serviço público";

$\mathrm{X}$ - Inciso IX do art. 65 (atribuição ao Poder Legislativo de legislar sôbre bers do domínio federal etc.);

XI - Art. 77 (competência do Tribunal de Contas para julgar as contas dos responsáveis por dinheiros e outros bens públicos, e as dos administradores das entidades autárquicas). (inciso II) (e julgar da legalidade dos contratos (inciso III), (parágrafos $10^{\circ}, 20^{\circ}$ e $30^{\circ}$ ). A competência do Tribunal de Contas cada vez mais se amplia no tocante a pessoas, quer públicas quer privadas, que têm a seu cargo a prestação de serviços públicos;

XII - Inciso VII do art. 87 (competência privada do Presidente da República para celebrar tratados e convençōes internacionais ad referendum do Congresso Nacional). Há casos de prestação e formas de exploração de serviços públicos que dependem de tratados e convenções além de contratos especisis. como sejam os do aproveitamento hidro-elétrico e distribuição de energia em zonas de fronteira, ferrovias internacionais, comunicações internacionais e outros, abrangendo países diferentes.

XIII - Parágrafo 10 do art. 141, pelo qual se declara que "os cemitérios terão caráter secular e serão administrados pela autoridade municipal". Poderão as associações religiosas, entretanto, manter cemitérios particulares, na forma da Lei. Parágrafo 16 do art. 141, que garante o direito de propriedade, "salvo o caso de desapropriação por necessidade ou utilidade pública, ou por interêsse social mediante prévia e justa indenização em dinheiro". 
O resto do dispositivo trata do assunto especial da desapropriaçăo, em caso de perigo iminente, como guerra ou comoção intestina.

XIV - Parágrafo 34 do art. 141, excluindo a tarifa aduaneira da obrigação de ser cobrada em cada exercício sem prévia autorização orçamentária.

XV - Parágrafo 38 do art. 141, que define a natureza de cada cidadão como parte legítima "para pleitear a anulação ou declaração de nulidade de atos lesivos ao patrimônio da União, dos Estadcs, dos municípios, das entidades autárquicas e das sociedades de economia mista".

XVI - Art 145: Organização da orđem econômica conforme os princípios da justiça social, de modo a conciliar "a liberdade de iniciativa com a valorização do trabalho humano".

XVII - Art. 146: Facultando a União o poder de intervir, mediante Lei especial, no domínio econômico. Faculta ainda êsse dispositivo $\sigma$ poder de monopolizar determinada indústria ou atividade, mas "a intervenção terá por base o interêsse público e por limite os direitos fundamentais" assegurados na Constituição. social;

XVIII - Art. 147, condicionando o uso da propriedade ao bem estar

XIX - Art. 148: repressão a tôda e qualquer forma de abuso do poder econômico. O abuso dêsse poder se refere especìficamente a êsses objetivos: domínio dos mercados nacionais e aumento arbitrário de lucros. Quanto a । aspecto formal, êsse abuso se caracteriza também nas Uniões ou agrupamentos de emprêsas, individuais ou sociais, "seja qual fôr a sua natureza".

$\mathrm{XX}$ - Art. 151: obrigatòriamente da disposição, por leis, sôbre o "regime das emprêsas concessionárias de serviços públicos federais, estaduais e municipais;

XXI - Parágrafo único đo art. 151. Nesse parăgratơ, consubstanciam-se diferentes modalidades de regulamentação dos serviços explorados por concessão, como sejam:

a) determinação da fiscalização;

b) determinação implícita, nessa fiscalizaçāo, da revisão đas tarifas;

c) a determinação da fiscalização, nesse sentido, deverá ser feita "a fim de que os lucros concessionários não exceda a justa remuneração do capital";

d) e que êsses lucros, dësse modo, permitam às emprêsas "atender a necessidade de melhoramentos e expansão dêsses serviços" explorados por concessão;

e) A Lei será aplicada às concessões feitas no regime anterior, isto é, antes da Constituição de 18 de setembro de 1946;

f) essa aplicação objetivará ainda as concessões "de tarıtas estipuladas para todo o tempo de duração do contrato";

XXII - Art. 152: O reconhecimento, como propriedade distinta da do solo, das minas e de mais riquezas do sub-solo, para efeito de exploração ou aproveitamento industrial; 
XXIII - Art. 153: Condicionamento do aproveitamento dos recursos minerais e de energia hidráulica à obrigatoriedade da autorização ou concessão federal na forma da Lei. O têrmo concessão, nesse dispositivo, parece não envolver o sentido contratual da palavra ligada à prestação de serviço público, de vez que especîficamente se relaciona ao "aproveitamento".

XXIV - Nos.parágrafos dêsse art. 153, as palavras "autorizaçöes" e "concessões", no plural como säo empregadas, parecem exprimir atos do govêrno federal, não contratos com a amplitude de sentido em que se enquadram as concessões clássicas de serviços. "Autorizações ou concessões", estatui o parágrafo $10^{\circ}$ : "Serão conferidos exclusivamente a brasileiros ou a socierlades organizadas no país, assegurada ao proprietário do solo preferência para exploração". No parágrafo $2 .^{\circ}$ estatui-se que "não dependerá de autorização ou concessão o aproveitamento de energia hidráulica de potência reduzida". Tudo indica, portanto, que as palavras "autorização" e "concessão" possuem, em face dêsses dispositivos, o mesmo sentido de ato administrativo, observando-se uma impropriedadae de terminologia.

XXV - Parágrafo $3 .^{\circ}$ do art. 153. Nesse parágrafo, admite-se a atribuiçãa, aos Estados, do poder de "autorização" ou "conceder" o aproveitamento dos recursos minerais, não apenas de promover êsse aproveitamento, desde que satisfaçam as exigências legais e, entre essas, "possuírem os necescários serviços técnicos e administrativos".

XXVI - Parágrafo $4 .^{\circ}$ do art. 153. Trata-se apenas de prover 0 auxílio, pela União aos Estados, em casơs de interêsse geral indicados por Lei, para a realização de estudos "referentes às águas termo-minerais, de aplicação medicinal e no aparelhamento das estâncias destinadas ao uso delas. Serviços ligados ao aproveitamento dessas águas e funcionamento das emprêsas na exploração e distribuição dêsses recursos podem possuir o "status" de Serviços de Utilidade Pública.

XXVII - Art. 155 e seu parágrafo único. Dispõem sôbre a nacionalização, não estatização, da "navegação de cabotagem para o transporte de mercadorias". Salvo em casos de necessidade pública, êsse serviço é privativo dos navios nacionais. Proprietários, armadores e comandantes e dois têrços, pelo menos, dos tripulantes dos navios nacionais, devem ser obrigatòriamente brasileiros.

XXVIII — Parágrafo $2 .^{\circ}$ do art. 156. Sôbre alienação ou concessão de terras públicas, o que não poderá ser feito sem prévia autorização do Senado Federal, desde que a área seja superior a 10 mil hectares.

XXIX - Inciso IV do art. 157. Dispõe sôbre "a participação objetiva e direta do trabalhador nos lucros da emprêsa, nos têrmos e pela forma que a Lei determinar".

$\mathrm{XXX}$ - Inciso XI do art. 157. Dispõe sôbre a "fixação das percentagens de empregados brasileiros nos serviços públicos dados em concessão e nos estabelecimentos de determinados ramos do comércio e da indústria";

XXXI - Art. 160. Veda a propriedade de emprêsas jornalísticas assim como as de rádio-difusão, a sociedades anônimas por ações ao portador e estrangeiros. 
XXXII - Inciso III do art. 168. Obrigatoriedade das emprêsas industriais, comerciais e agrícolas, em que trabalhem mais de 100 pessoas, de "manter ensino primário gratuito para os seus servidores e filhos dêstes";

XXXIII - Inciso IV do art. 168. Obrigatoriedade das emprêsas, industriais o comerciais, de ministrar "aprendizagem aos seus trabalhadores menores, pela forma que a Lei estabelecer, respeitando os direitos dos profes. sôres";

XXXIV - Incisos I, II e III do art. 180, segundos os quais não se permitirá nas zonas indispensáveis à defesa do país, sem prévio assentimento do Conselho de Segurança Nacional:

a) "Qualquer ato referente a concessão de terras, a abertura de vias de comunicação e a instalação de meios de transmissão";

b) "A construção de pontes e estradas inter-nacionais";

c) "O estabelecimento ou exploração de quaisquer indústrias que interessem à segurança do país". Êsse inciso é complementado pelos parágrafos $10^{\circ}$ e $2 .^{\circ}$ dos mesmos, principalmente sôbre a parte de nacionalização, quase total de capitais e trabalhadores;

XXXV - Parágrafo $3 .^{\circ}$ do art. 181. Sôbre obrigatoriedade de prova de alistamento, de ser reservista ou estar isento do serviço militar a qualquer brasileiro, como conđições para exercer função pública ou ocupar emprêgo em entidade autárquica, sociedades de economia mista ou emprêsa concessionária de serviço público;

XXXVI - Artigo 198 e parágrafos $10^{\circ}$ e $20^{\circ}$ e artigo 199 e seu parágrafo único sôbre planificação em regiões do país (plano de defesa contra os efeitos da sêca do nordeste e plano de valorização econômica da Amazônia). $\mathrm{Na}$ execução dêsses planos, para os quais são atribuídos recursos resultantes de percentagem defindas da renda tributária nacional, verifica-se a manifestação de serviços públicos pròpriamente ditos e serviços de utilidade pública sob a mais variada forma de prestação);

XXXVII - Inciso V do art. 209. Dispõe sôbre a intervenção nas em. prêsas de serviços públicos, pelo Presidente da República, durante o Estado de sítio.

\section{VII - CONCLUSÃo}

A rigorosa análise do texto da Constituição, da maneira como até aqui foi feita com o objetivo de levantamento de dispositivos aplicáveis aos serviços de utilidade pública, serve também para acentuar, por um lado, a existência de disposições, que são de natureza constitucional apenas porque figuram na Constituição, mas que melhor se enquadrariam em leis complementares, orgânicas ou especiais. Por outro lado, comprova-se que o Estado, além de poder interferir com a maior amplitude de ação possível no domínio econômico, imiscui-se constitucionalmente na própria vida íntima das emprêsas, tanto coibindo excessos de lucro como restringindo as operações de gerência privada pela imposição de medidas que amoldou o exercício das funções administrativas às normas de trabalho, formação de capitais, condições de em- 
prêgo e prestação obrigatória de serviços que se excluem dos objetivos existenciais das organizações.

O resultado é que muitos dêsses dispositivos ainda não encontraram aplicabilidade prática, continuam apenas a figurar no Texto, como se fôssem simples recomendações, conforme acontece, por exemplo, com a mudança da Capital Federal, cujo artigo tem passado de Constituição, para Constituição, de regime para regime, sem nenhuma efetivação real.

Além do mais, principalmente no tocante aos serviços públicos explorados sob sistema de concessão, a aplicação de alguns, dispositivos implicará fatalmente em revisões tarifárias, como a transferência das responsabilidades de certos ônus e obrigações ao próprio público consumidor de produtos-serviços.

Finalmente, por nos referirmos às concessões, estabelecemos os seguintes. enunciados que servem de elementos de caracterização e distinção em face to Direito Brasileiro, tendo em vista as variadas formas de prestação do Serviço Público: blico:

a) Tradicionalmente se tem considerado, no Brasil, como Serviço Pú-

$1^{\circ}$ ) o que é prestado, direta ou indiretamente, pelo Estado (União, Estado-membro, Território, Município, Distrito);

$2 .^{\circ}$ ) o que é objeto de concessão, arrendamento, e outras formas;

b) Nesse último caso, o Serviço Público é prestado por pessoas jurídicas de Direito Privado, convindo acentuar que, em se tratando de concessão, o Serviço Público é objeto de emprêsas ou grupos de emprêsas geralmente monodolisticas ou com características de monopólios legais;

c) A par dessas modalidades clássicas, concessão e arrendamento, o Serviço Público é também prestado por pessoas jurídicas de direito privado, sob outras formas legais, como resultantes de atos, de licenças e autorizações. especiais;

d) Mas além dessas pessoas jurídicas de Direito Privado, há outras que nrestam Serviço Público perfeitamente caracterizado;

e) Não é, portanto, a forma de prestação que caracteriza o Serviço como de natureza pública;

f) Dêsse modo, o Serviço Público não é uma cratura de ato ou contrato, pouco interessando, como elemento de caracterização, a forma jurídica nu administrativa pelo qual é prestađo;

g) O serviço público é, além de tudo, uma criatura de Status;

h) Sendo embora difícil estabelecer rigorosamente os limites de distinçăo entre o Serviço Público Privado, e apesar de ser mais fácil distinguir a pessoa jurídica de Direito Público do Direito Privado segundo as normas legais, - o Serviço Público se manifesta por elementos evidentes que the imprimem êsse "status";

i) A regulamentação, portanto, ou melhor, o contrôle especial do Estadn, deve se manifestar além das formas tradicionais de intervenção, de modo 
a envolver tôdas as pessoas jurídicas que prestam atividades caracterìsticamente inerentes ao "status" de serviçơ público;

j) Ao Estado assiste o direito de regulamentar tôdas as atividades reconhecidamente como públicas ou privadas. Mas em se tratando de Serviços com "status" público, não basta apenas essa regulamentação que decorre fundamentalmente do Poder de Polícia. E' necessário, ainda, o exercício de um contrôle especial inerente às manifestações da soberania e no interêsse das coletividades, de modo a conciliar os direitos do indivíduo com os direitos do Estado.

k) A Constituição, mesmo vagamente, tratou dessa conciliação, consubstanciando dispositivos que, pela sua própria natureza, já representam normas especiais de regulamentação e contrôle.

\section{SUMMARY}

A close analysis of the Constitution reveals the existence of provisions that are conssitutional only because they are embodied in the Constitution, although they should rather be the object of complementary legislation. Such analysis also evidences that the State, besides interfering in the field of Economy, with the widest possible freedom of action, involves itself in the internal life of the business corporations, either prohibittng excessive profit or testricting the operations of private manadement, through measures which impose the performance of adminisrative acts in accordance with certain norms regulating labour, capital formation, employment conditions and compulsory carrying out of services not comprised within the purpose of such business corporations.

Consequently, a great many of those provisions have not been applied as yet, being included in the Constitution as if they were but mere recommendations, viz., that which deals with the changing of the Federal Capital to the hinterland. Moreover, especially with respect to public services entrusted to concessionary companies, the application of certain provisions such as, for example, the transfer of some charges and obligations to the of the services, would necessarily imply tariff revision.

We have made the following statements as regards concessions, which may help as characterizing elements in the Brazilian law, having in view the different kinds of public services:

a) It has been traditionally considered as public services, in Brazil; (1) those which are direct or indirectly performed by the State (Federal Union, State, Territory, MuniciDality, District); (2) those which may be the object of concessions, renting, etc.).

b) In the second altednative, public service is performed by juridical persons of private law. It should be emphansized that, in case of concessions, public service is the object of companies or graups of companies, generally monopolistic in nature, or having the cha. racteristics of legral monopolies.

c) Besides those classical types, concession and renting, public service is also performed by juridical persons of private law, under some other legal forms. It results from acts, ticences and special authorizations.

d) Side by side with those juridical persons of private law, others exist which perform perfectly characterized public service.

e) It is not the manner of performing the service which characterizes it as public.

f) Public service, therefore, is not a creation of an act or contract, and it matters little, as a characterizing element, the nature of the juridical or administrative law through which it is performed. 
g) Public service is, moreover, the creation of a status.

h) Although being difficult to establish a cleat dividing line between public and private service, as it is easier to distinбuish between juridical persons of public law from those of private law, according to legal norms, public service expresses itself through obvious elements which lend it its status.

i) Consequently, regulatory activities, os better, the special controls exercised by the State, must possess other types different from the traditional intervention, in order to comprise every juridical person that perform any activity characteristically inherent to the status of public service.

j) The State has the right to regulate every activity recognized either as public or private. Yet as regards services having public status, such regulation, which derives fundamentally from the police power of the State, is not sufficient. The exercise of a special control derives from the manifestations of sovereignty, is also necessary in the interest of society, in order to reconcile the individual rights and the rights of the State.

k) The Constitution, although not expressly, has dealt with such reconciling, for it embodies provisions which, by their very nature, actually are special norms of regulation and control.

A vitalização da vida municipal entre nós será mais fruto de idéias e atitudes, que de providências imediatas, embora estas últimas jamais devam ficar à margem. Esta afirmação vale como uma, preliminar básica, um fundamento sôbre o qual deverá repousar a já vitoriosa, mas, ainda, muito necessitada campanha municipalista brasileira.

Luciano F. Mesquita, O Desenvolvimento Nacional e o Municipio Diretrizes e Bases da Operação Município. 